\title{
Art therapy using famous painting appreciation maintains fatigue levels during radiotherapy in cancer patients
}

\author{
Woong Sub Koom, MD, PhD ${ }^{1,2^{*}}$, Mi Yeon Choi, $\mathrm{MA}^{3^{*}}$, Jeongshim Lee, $\mathrm{MD}^{1}$, Eun Jung Park, $\mathrm{BA}^{3}$, \\ Ju Hye Kim, $\mathrm{BS}^{3}$, Sun-Hyun Kim, PhD ${ }^{3+}$, Yong Bae Kim, MD, PhD ${ }^{1+}$ \\ 'Department of Radiation Oncology, Yonsei University College of Medicine, Seoul; \\ ${ }^{2}$ Cancer Information Center, Yonsei Cancer Center, Yonsei University Health System, Seoul; \\ ${ }^{3}$ Graduate School of Clinical Art Therapy, CHA University, Pocheon, Korea
}

\begin{abstract}
Purpose: The purpose of this study was to evaluate the efficacy of art therapy to control fatigue in cancer patients during course of radiotherapy and its impact on quality of life (QoL).

Materials and Methods: Fifty cancer patients receiving radiotherapy received weekly art therapy sessions using famous painting appreciation. Fatigue and QoL were assessed using the Brief Fatigue Inventory (BFI) Scale and the Functional Assessment of Chronic IIIness Therapy-Fatigue (FACIT-F) at baseline before starting radiotherapy, every week for 4 weeks during radiotherapy, and at the end of radiotherapy. Mean changes of scores over time were analyzed using a generalized linear mixed model.

Results: Of the 50 patients, 34 (68\%) participated in 4 sessions of art therapy. Generalized linear mixed models testing for the effect of time on mean score changes showed no significant changes in scores from baseline for the BFI and FACIT-F. The mean BFI score and FACIT-F total score changed from 3.1 to 2.7 and from 110.7 to 109.2, respectively. Art therapy based on the appreciation of famous paintings led to increases in self-esteem by increasing self-realization and forming social relationships.

Conclusion: Fatigue and QoL in cancer patients with art therapy do not deteriorate during a period of radiotherapy. Despite the single-arm small number of participants and pilot design, this study provides a strong initial demonstration that art therapy of appreciation for famous painting is worthy of further study for fatigue and QoL improvement. Further, it can play an important role in routine practice in cancer patients during radiotherapy.
\end{abstract}

Keywords: Cancer, Radiotherapy, Art therapy, Fatigue, Quality of life, Oncology

\section{Introduction}

Fatigue, which is defined as deficits in energy, mental capacity, and psychological status, is more commonly observed in cancer patients than others [1]. The majority of patients with advanced cancer experience fatigue as the most prevalent symptom [2,3]. Fatigue may be caused by cancer itself as well as pre-existing physical and psychological factors $[3,4]$. In

Received 1 April 2016, Revised 22 April 2016, Accepted 9 May 2016.

Correspondence: Yong Bae Kim, MD, PhD, Department of Radiation Oncology, Yonsei University College of Medicine, 50-1

Yonsei-ro, Seodaemun-gu, Seoul 03722, Korea. Tel: +82-2-2228-8115, Fax: +82-2-2227-7823, E-mail: ybkim3@yuhs.ac

Sun-Hyun Kim, PhD, Graduate School of Clinical Art Therapy, CHA University, 120 Haeryong-ro, Pocheon 11160, Korea.

Tel: +82-31-881-7026, Fax: +82-31-881-7077, E-mail: kshcat1210@hanmail.net

*Woong Sub Koom and Mi Yeon Choi are contributed for this work equally.

†Yong Bae Kim and Sun-Hyun Kim are contributed for this work equally.

(c) This is an Open Access article distributed under the terms of the Creative Commons Attribution Non-Commercial License (http://creativecommons.org/ licenses/by-nc/4.0/) which permits unrestricted non-commercial use, distribution, and reproduction in any medium, provided the original work is properly cited.

www.e-roj.org 
addition, cancer treatments are clearly one cause of fatigue [5]. During anti-neoplastic treatment, 100\% of patients become fatigued [6]. Radiotherapy is performed over a period of several weeks, resulting in side effects impairing nutrition and general condition [7]. Fatigue occurrence increases over the course of radiotherapy $[8,9]$. Irrespective of the cause, fatigue is frequently associated with anxiety, depression, sleep disturbance, and low degrees of physical functioning $[10,11]$. Overall quality of life $(\mathrm{OoL})$ and the patient's ability to cope with their illness also decrease [12]. Furthermore, severe fatigue may lead to discontinuation of treatment $[9,13]$.

Art therapy is defined as a mind-body intervention supporting the 'power of the mind to influence the body in ways which encourage and stimulate health and well-being' $[14,15]$. As a form of cancer management, art therapy can contribute to cancer patients improving their ability to cope with the difficulties of cancer treatment and adapt to stressful conditions from cancer care $[16,17]$. Psychological benefits of art therapy have been suggested in empowering individuals to recalibrate their sense of self, the adjustment process, and perceptions of stress [17-20]. Some of the effects can reduce negative symptoms regarding anxiety and depression, as well as increase feelings of energy $[15,21,22]$. Only half of cancer patients with fatigue from radiotherapy were recommended for an intervention, such as relaxation therapy and group psychotherapy [12]. Although recognition and caring for fatigue is an important and fundamental aspect of cancer management [3], only a few studies have quantified the impact of fatigue in cancer patients receiving radiotherapy.

The purpose of this study was to evaluate the efficacy of art therapy to control fatigue in cancer patients during course of radiotherapy and its impact on QoL. We hypothesized that art therapy would prevent the deterioration of fatigue during radiotherapy.

\section{Materials and Methods}

\section{Study population}

This trial was conducted at the Yonsei Cancer Center, Yonsei University College of Medicine in collaboration with faculty from the Graduate School of Clinical Art Therapy, CHA University. We used a prospective design and received approval from the Institutional Review Boards of the Yonsei Cancer Center, Yonsei University College of Medicine. We recruited adult ambulatory patients of the Department of Radiation Oncology between January 2015 and April 2015. Eligibility criteria included the following: scheduled to receive 4 or more weeks of external-beam radiotherapy, older than 20 years, and able to understand questionnaires. Exclusion criteria included uncontrolled co-morbid medical or psychiatric illness, metastatic disease, poor performance (Eastern Cooperative Oncology Group $[\mathrm{ECOG}]>2$ ); and severe anemia (hemoglobin $<9 \mathrm{~g} / \mathrm{dL}$ ).

\section{Art therapy}

The therapy program utilized in this study involved the following elements: art therapy based on the appreciation of famous paintings conducted across four 15-minutes sessions once a week, as well as a one-to-one interview between the therapist and patient in a separate therapy room prior to radiotherapy. In order to reduce an anxiety for treatment room, art therapy was started before 30 minutes of radiotherapy appointment. The art therapy was conducted at least once a week for 4 weeks. The therapists and patients were randomly assigned in the first session, and the assigned pairs did not change throughout the program unless the patients had special wishes. Seventeen students, who major in art therapy, conducted art therapy and interviewed patients. In each session, one of the artworks was preselected as the object of therapy for that session. The patient expressed the feelings aroused by images of the painting, and the therapist inferred the patient's emotional, affective, and mental states based on his/her predilection when choosing the artwork and expression of the emotions aroused by the image of the painting. Art therapists led the process of artistic expression and interviewed the patients with the following processes: first introduction part, 1) viewing famous paintings to arouse interest in paintings and explore the images offered by them; 2) talking about the experiences of seeing paintings similar to the one chosen by the patient; 3) talking about the reasons for choosing the painting. Second activity part, 1) exploring the aesthetic elements used in the painting (colors, lines, and spatial composition); 2) imagining the artist's intention expressed through the painting; and 3) talking about the patient's feelings on seeing the painting. Third conclusion part, 1) talking about the emotions felt before and after the activities. The famous paintings were selected by an expert panel of three and clinical art therapists who had experience of implementing three or more art therapy sessions. An important selection criterion was that paintings were easy to understand and interesting for patients. Questions to aid selection were as follows: Is the painting related to the topic? Are the expression techniques and contents related to the topic? Is the painting easy for the patients to understand? Can 
Table 1. List of the selected paintings

\begin{tabular}{|c|c|}
\hline Session & Paintings \\
\hline $\begin{array}{l}\text { 1. Landscape } \\
\text { painting }\end{array}$ & $\begin{array}{l}\text { Field with Poppies (Vincent Van Gogh, 1889) } \\
\text { Houses at Argenteuil (Claude Monet, 1873) } \\
\text { Banks of Seine Vetheuil (Claude Monet, } \\
\text { 1880) } \\
\text { Poplars on the Bank of the River Epte Tree } \\
\text { Lake (Claude Monet, 1891) } \\
\text { View of I'Estaque and the If Castle (Paul } \\
\text { Cézanne, 1885) }\end{array}$ \\
\hline 2. Figure painting & $\begin{array}{l}\text { The Child's Bath (Mary Cassatt, 1884) } \\
\text { Motherhood (Mary Cassatt, 1890) } \\
\text { Woman with a Parasol-Madame Monet and } \\
\text { Her Son (Claude Monet, 1875) } \\
\text { Love at First Sight (Arthur John Elsley, 1874) } \\
\text { Meadow at Bezons, (Claude Monet, 1874) } \\
\text { Ask Me No More (Lawrence Alma Tadema, } \\
\text { 1906) }\end{array}$ \\
\hline $\begin{array}{l}\text { 3. Color-centered } \\
\text { painting }\end{array}$ & $\begin{array}{l}\text { Sunflowers (Vincent Van Gogh, 1888) } \\
\text { Polynesia, the Sea (Henri Matisse, 1946) } \\
\text { Squares with Concentric Rings (Wassily } \\
\text { Kandinsky, 1913) } \\
\text { Water Lily Pond, Symphony in Green (Claude } \\
\text { Monet, 1899) }\end{array}$ \\
\hline $\begin{array}{l}\text { 4. Christian paint- } \\
\text { ing }\end{array}$ & $\begin{array}{l}\text { The Infant Samuel (Joshua Reynolds, 1776) } \\
\text { Praying Hands (Albrecht Durer, 1508) } \\
\text { A Riverside Where I Can Rest (Yong Sung } \\
\text { Kim, 2005) } \\
\text { The Good Shepherd (Anonymous) } \\
\text { The Virgin in Prayer (II Sassoferrato, about } \\
\text { 1640-1650) }\end{array}$ \\
\hline
\end{tabular}

the painting attract patients' interest? Can the painting evoke patients' internal motives? Are aesthetic elements clearly expressed? The famous paintings consisted of a landscape painting in the first session, a figure paintingin the second session, a color-centered painting in the third session, and a Christian painting in the fourth session. Table 1 lists the selected paintings. A total of 21 famous paintings were used as therapy materials for the 4 sessions of the program. They were printed in resolutions of $300 \mathrm{dpi}$ or higher and offered in real-size frames. The illumination of the therapy room was kept at the same level throughout the program. The paintings were placed at a distance of $50 \mathrm{~cm}$ from the patient, facing the therapist and patients in the same direction.

\section{Assessment}

All the patients were asked to fill the questionnaires at baseline before starting radiotherapy, every week for 4 weeks during radiotherapy, and at the end of radiotherapy. Fatigue and $\mathrm{OoL}$ was assessed using the Brief Fatigue Inventory (BFI) and the Functional Assessment of Chronic IIIness Therapy-Fatigue (FACIT-F). The BFI was used for fatigue assessment and consists of 9 items that ask participants to rate the severity of current, usual, and worst fatigue and how much it interfered with their lives during the previous 24 hours. Fatigue and its interference are measured on a 0-10 scale, where 0 represents "no fatigue" and 10 denotes "as bad as you can imagine." The BFI score is calculated from the mean of the 9 items. Higher scores on the $\mathrm{BFI}$ represent worse fatigue. The validity and reliability of the BFI has been established $[23,24]$. The FACIT-F contains 40 items, where are the Functional Assessment of Cancer Therapy (FACT-G) instrument and additional fatigue-specific items $[25,26]$. The FACT-G consist of 4 primary QoL domains: physical well-being (PWB; 7 items), social/family well-being (SWB; 7 items), emotional well-being (EWB; 6 items), and functional well-being (FWB; 7 items). The fatigue subscale (FS) contains 13 items. It generates FACIT-F trial outcome index (TOI), FACT-G total score, and FACIT-F total score. The total FACT-G score is obtained by summing individual subscale scores (PWB $+E W B+S W B+F W B)$. The TOI is the sum of the PWB, FWB and FS score. Total scores for FACIT-F are obtained by summing all subscale scores (PWB + EWB + SWB + FWB + FS score). Higher scores for the scales and subscales indicate better QoL.

\section{Statistics}

A change was defined as the baseline value minus the value at each week during radiotherapy for each scale. Means and standard deviations were used to present the results. The overall impact of art therapy over time was evaluated using generalized linear mixed modeling for the $\mathrm{BFI}$ and each score from the FACIT-F. The mean values for scores at specific time points were plotted graphically. No adjustments for missing data were made beyond the use of generalized linear mixed modeling. All statistical tests were two sided, with significance level of 0.05 .

\section{Results}

\section{Compliance and baseline characteristics}

Between January 2015 and April 2015, 50 patients were eligible and willing to participate in the study. Of these, only 34 (68\%) participated in 2 or more sessions. Sixteen patients withdrew this study due to lack of interest. All 34 patients completed 4 sessions of art therapy. We analyzed the data of these 34 patients, which were appropriate for evaluate the effect of art therapy. Baseline characteristics are presented in Table 2. 
The median age was 50 years (range, 34 to 68 years) and patients had a good performance status (ECOG, 0 or 1). Breast cancer patients were most common. There was no recurrent cancer patient and most patients had cancer treatment duration of less than 1 year. All patients received radiotherapy for curative, not palliative purposes. Baseline fatigue was mild to moderate with a mean BFI score of $3.1(\max , 10)$ and FS score of 39.1 ( $\max , 52$ ). However, 50\% answered that they had fatigue irrespective of severity. There was no significant relationship between baseline fatigue and clinical factors.

\section{Assessment of the impact of art therapy on fatigue over time}

Table 3 demonstrates change scores at weekly time points during radiotherapy. Fig. 1 and Table 4 show these findings for the BFI and each FACIT-F domain. Generalized linear mixed modeling testing for the effect of time on mean change scores showed no significant worsening of scores from baseline for BFI and FACIT-F. Although statistical significance was not reached, art therapy decreased mean BFI scores during radiotherapy (from 3.1 to 2.7). For the FACIT-F, most summed scores (FACIT-F TOI, FACT-G, and FACIT-total) showed a similar pattern. No statistically significant change was observed. However, 4 primary QoL domains of FACT-G and FS showed a different change patterns during radiotherapy. PWB and FS slightly decreased, indicating worse QoL. On the contrary SWB, EWB, and FWS slightly increased, indicating better OoL. There were no associations between clinical factors and change in fatigue score at any time point in generalized mixed model.

\section{Perceptions of art therapy}

After the art therapy program was completed, a survey was conducted with the 34 patients who participated in all four art therapy sessions. The exit-interview questionnaire showed that all of patients indicated that the art therapy program was helpful and that they would recommend it to others. The item, "What is the most important thing that has happened?" in Table 5 was analyzed using the session notes that were used to record the progress of the art therapy program. It was found that the number for "express inner emotion" and "enhance and explore self-expression" were higher than those for other items, at $73(24.8 \%)$, and $71(24.2 \%)$, respectively. This indicates that the patients utilized the art as a medium through which they could reflect on their own mentality or situation, provide an opportunity for internal self-expression, and facilitate selfexpression. However, "help take mind off pain or discomfort" $(2.7 \%)$ was shown to be lower than most other items. The
Table 2. Baseline characteristics of the study population $(n=34)$

\begin{tabular}{|c|c|}
\hline Variable & Value \\
\hline \multicolumn{2}{|l|}{ Sex } \\
\hline Male & $6(17.6)$ \\
\hline Female & $28(82.4)$ \\
\hline Age (yr) & $50(34-68)$ \\
\hline \multicolumn{2}{|l|}{ ECOG performance status } \\
\hline 0 & $18(52.9)$ \\
\hline 1 & $16(47.1)$ \\
\hline Body mass index $\left(\mathrm{kg} / \mathrm{m}^{2}\right)$ & $23(18.4-31.6)$ \\
\hline \multicolumn{2}{|l|}{ Marital status } \\
\hline Married & $32(94.1)$ \\
\hline Unmarried & $2(5.9)$ \\
\hline \multicolumn{2}{|l|}{ Living status } \\
\hline Living together & $34(100)$ \\
\hline Not co-habiting & $0(0)$ \\
\hline \multicolumn{2}{|l|}{ Primary cancer } \\
\hline Breast & $22(64.7)$ \\
\hline Rectal & $11(32.4)$ \\
\hline Prostate & $1(2.9)$ \\
\hline \multicolumn{2}{|l|}{ Stage } \\
\hline 0 & $4(11.8)$ \\
\hline I & $11(32.4)$ \\
\hline$\|$ & $7(20.5)$ \\
\hline III & $12(35.3)$ \\
\hline \multicolumn{2}{|l|}{ White blood cell $(/ \mu \mathrm{L})$} \\
\hline Before RT & $5,756 \pm 2,086$ \\
\hline After RT & $4,602 \pm 1,639$ \\
\hline \multicolumn{2}{|l|}{ Hemoglobin (g/dL) } \\
\hline Before RT & $12.9 \pm 1.7$ \\
\hline After RT & $12.9 \pm 1.5$ \\
\hline Total dose of RT (Gy) & $52.5(50.4-60.4)$ \\
\hline Fraction number of RT & $28(21-33)$ \\
\hline \multicolumn{2}{|l|}{ Fraction dose of RT (Gy) } \\
\hline Fraction dose & $1.8(1.8-2.4)$ \\
\hline $1.8-2.0$ & $21(61.8)$ \\
\hline$>2.0$ & $13(38.2)$ \\
\hline \multicolumn{2}{|l|}{ Site of RT } \\
\hline $\begin{array}{l}\text { Breast or chest wall with/without } \\
\text { regional LN, Iymph node; area }\end{array}$ & $22(64.7)$ \\
\hline Pelvis & $12(35.3)$ \\
\hline \multicolumn{2}{|l|}{ Surgery } \\
\hline Before RT & $23(67.6)$ \\
\hline No & $11(32.4)$ \\
\hline \multicolumn{2}{|l|}{ Chemotherapy } \\
\hline Before RT & $10(29.4)$ \\
\hline Concurrent & $11(32.4)$ \\
\hline No & $13(38.2)$ \\
\hline \multicolumn{2}{|l|}{ Hormone therapy } \\
\hline Before RT & $21(61.8)$ \\
\hline Concurrent & $21(61.8)$ \\
\hline No & $13(38.2)$ \\
\hline
\end{tabular}

Values are presented as median (range) or number (\%) or mean \pm standard deviation. ECOG, Eastern Cooperative Oncology Group; $\mathrm{RT}$, radiotherapy. 


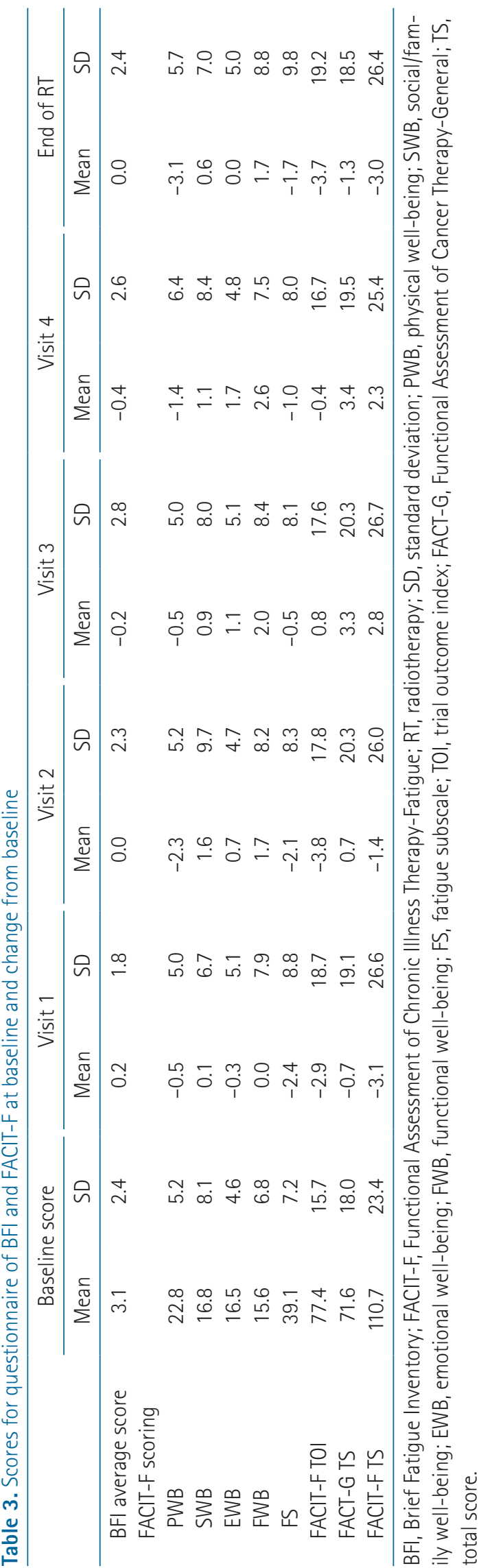

http://dx.doi.org/10.3857/roj.2016.01760

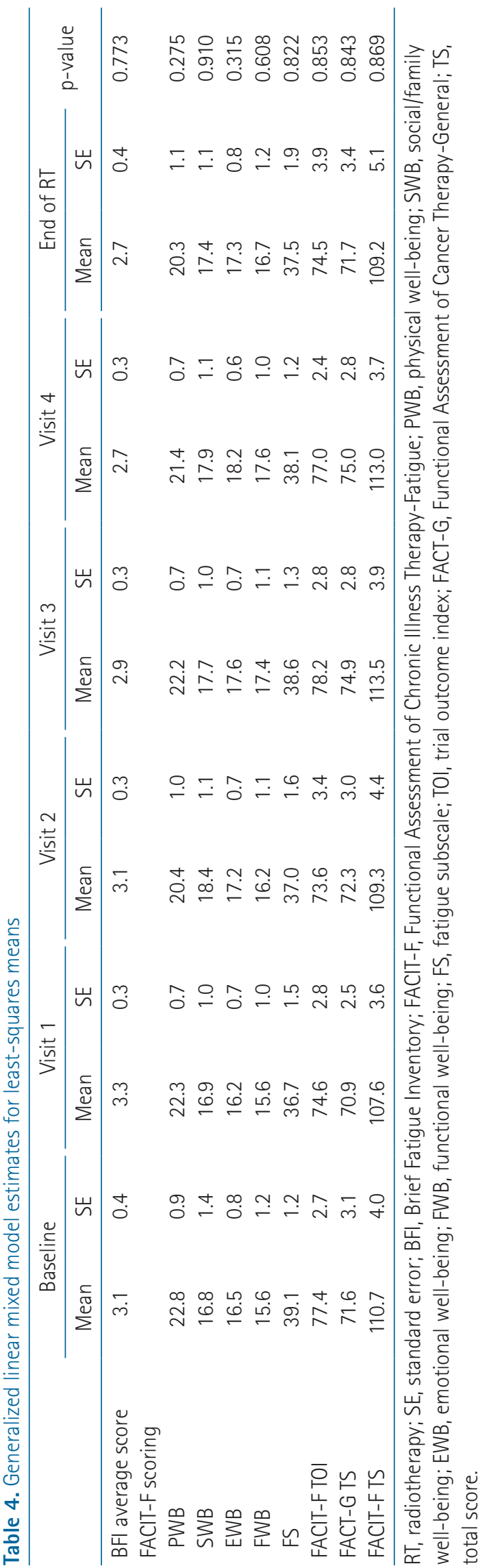

www.e-roj.org 
item "enhance coping mechanism" was also found to be lower than other items. The art therapy based on the appreciation of famous paintings led to increases in self-esteem by increasing self-realization and forming social relationships.
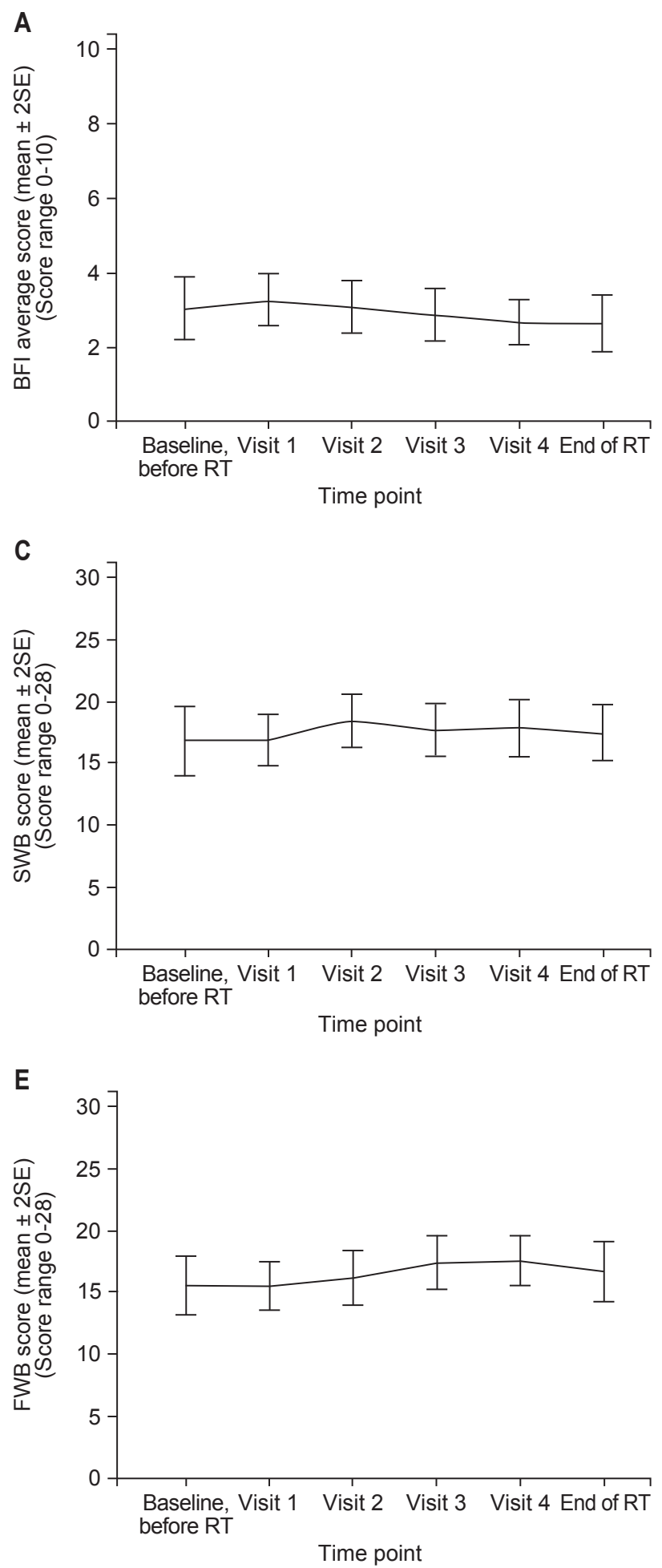

\section{Discussion and Conclusion}

This was a study assessing the impact of art therapy on fatigue during the radiotherapy period. Although some patients
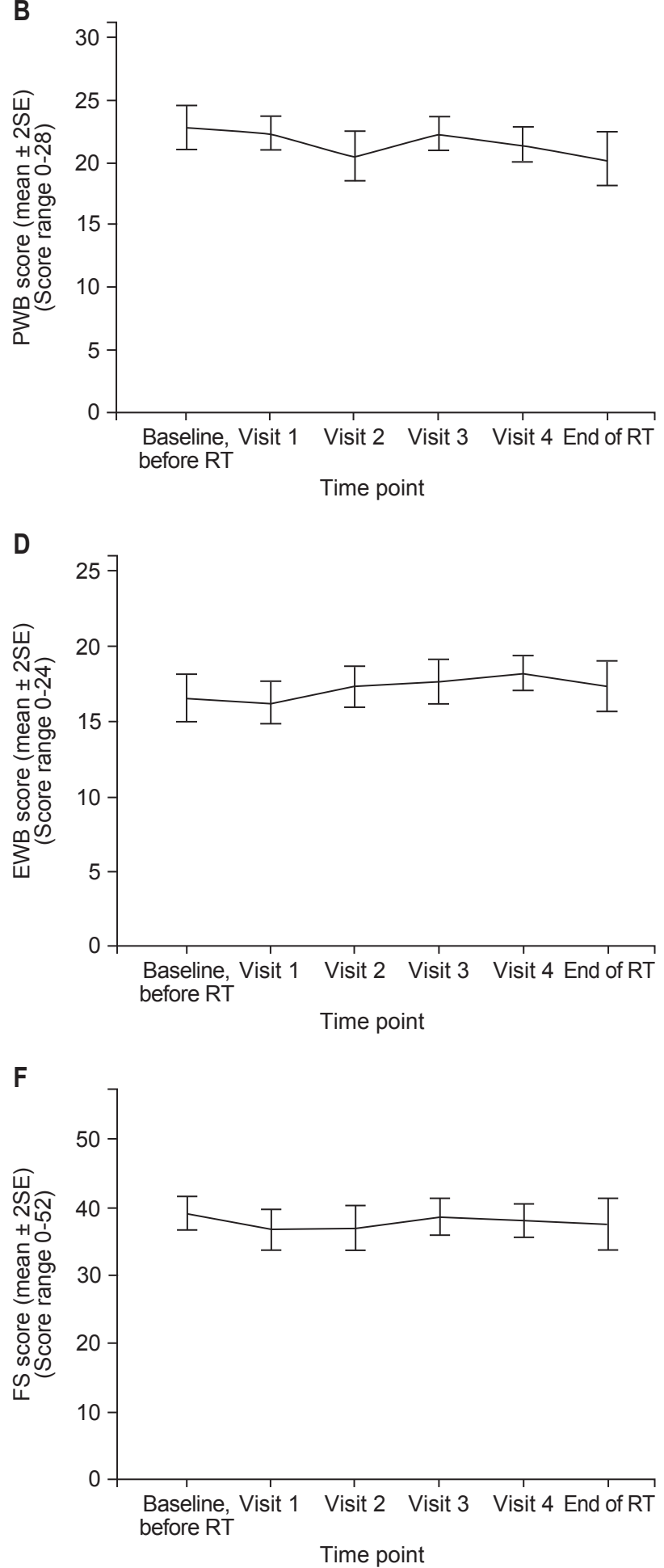

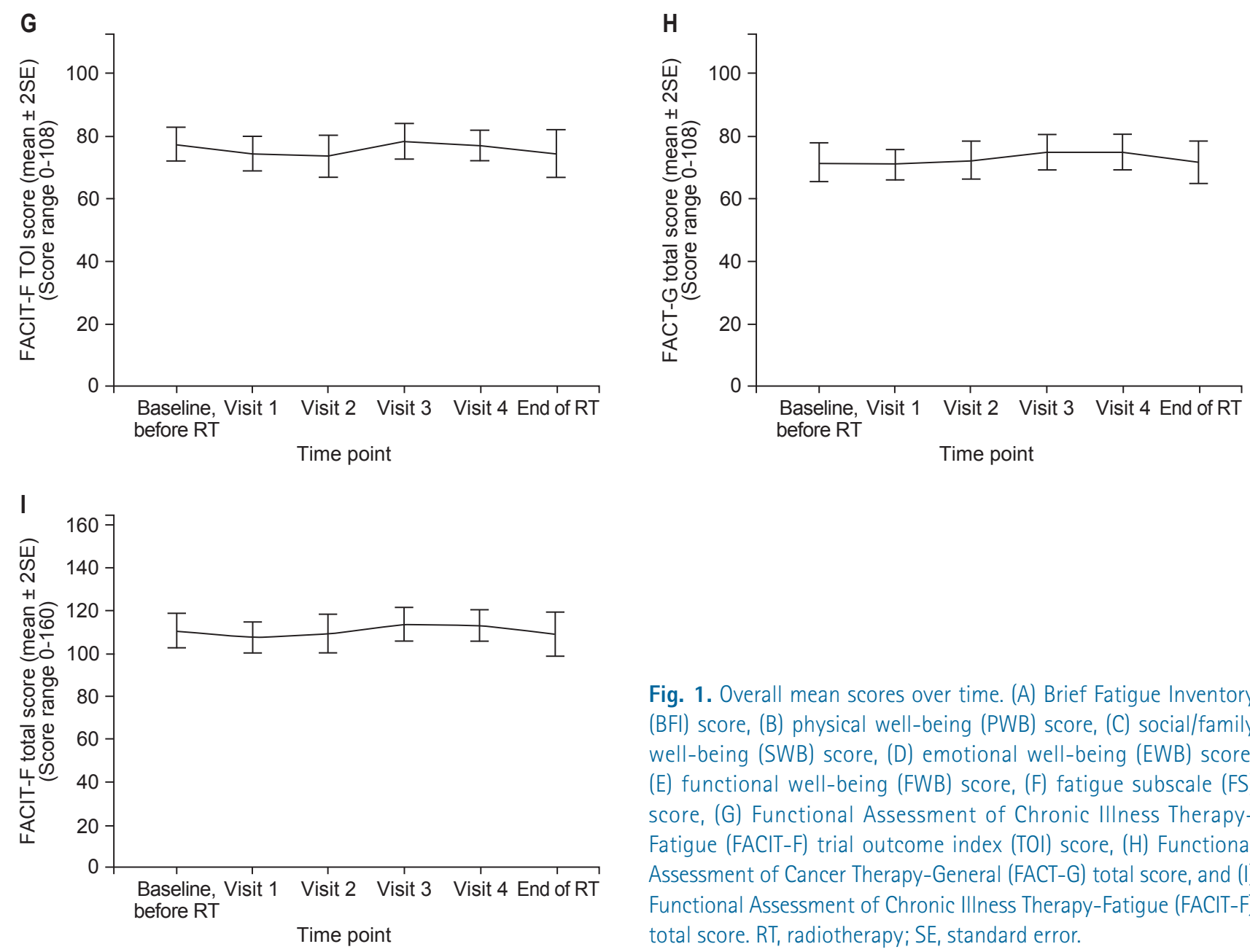

Fig. 1. Overall mean scores over time. (A) Brief Fatigue Inventory (BFI) score, (B) physical well-being (PWB) score, (C) social/family well-being (SWB) score, (D) emotional well-being (EWB) score, (E) functional well-being (FWB) score, (F) fatigue subscale (FS) score, $(G)$ Functional Assessment of Chronic Illness TherapyFatigue (FACIT-F) trial outcome index (TOI) score, (H) Functional Assessment of Cancer Therapy-General (FACT-G) total score, and (I) Functional Assessment of Chronic Illness Therapy-Fatigue (FACIT-F) total score. RT, radiotherapy; SE, standard error.

Table 5. Survey assessing perceptions of art therapy $(n=34)$

\begin{tabular}{lc}
\hline \multicolumn{1}{c}{ Exit interview questions } & No. $(\%)$ \\
\hline Was art therapy helpful? & $34(100)$ \\
1. Yes & $0(0)$ \\
2. No & \\
Would you recommend art therapy? & $34(100)$ \\
1. Yes & $0(0)$ \\
2. No & \\
What is the most important thing that has happened?) & $73(24.8)$ \\
1. Express inner emotion & $71(24.2)$ \\
2. Enhance and explore self-expression & $37(12.6)$ \\
3. Communicate emotions & $32(10.9)$ \\
4. Enhance treatment or life will & $22(7.5)$ \\
5. See the importance of living and appreciate present living & $22(7.5)$ \\
6. Help improve relationship with other people: which could control anxiety, depression, and low self-esteem & $22(7.5)$ \\
7. Help control symptoms (anxiety, depression, and pain) and increase quality of life & $8(2.7)$ \\
8. Help take mind off pain or discomfort & $7(2.4)$ \\
9. Enhance coping mechanism &
\end{tabular}

${ }^{a)}$ Multiple choice question. 
dropped out, enrolled patients seemed to be interested in the appreciation of famous painting to control fatigue and emotional distress. Most patients demonstrated no deterioration of fatigue and found the weekly art sessions to be relaxing during the radiotherapy.

Fatigue is considered one of the most frequent side effects in cancer patients undergoing radiotherapy [27-29]. The proportion of patients expressing fatigue during radiotherapy is increasing in various cancer types $[30,31]$. The fatigue starts increasing from the second week onwards and decreases subsequently at around 4 weeks after completion of radiation $[9,12]$. It is also closely related to acute radiation effects, which alter the patient's nutrition and blood parameters such as anemia, leading to aggravation of baseline fatigue [9]. Its prevalence can reach up to $80 \%$ when patients are undergoing radiotherapy [32]. This may cause a decrease in self-esteem as well as in social activities, becoming a factor that negatively affects patients' OoL [29]. Despite its high prevalence, fatigue has not been measured routinely in cancer patients [24]. In a Korean study, compared with the normal group, the cancer patient group showed higher fatigue scores [24]. In this study, current fatigue, usual fatigue, and worst fatigue on the BFI were comparable to those previously reported in studies on Korean cancer patients. However, the fatigue levels of our participants on the FACIT-F subscale (FS) were better than those published for patients with breast cancer receiving radiotherapy [5]. Based on this observation, fatigue is problematic for patients preparing radiotherapy, and appropriate clinical interventions are needed.

Art therapy is a form of psychotherapy aimed at increasing well-being and psychological functioning, and it has a significant benefit for cancer patients, providing a mindbody interaction for communication and expression [20]. It is also an attribute of self-care and self-management empowerment for those living with cancer $[20,33]$. Wood et al. [20] reported quantitative and qualitative evidence for the use of art therapy in the management of emotional, physical, functional, social, and spiritual symptoms in adults with cancer [17]. The most notable benefits from art therapy were spiritual and psychological well-being [17]. Moreover, there have been several reports that art therapy reduced the severity of a broad spectrum of symptoms common in cancer patients, including decreased levels of anxiety, depression, and stress; significant improvement of social functioning; and improved OoL $[15,21,22]$. In oncology outpatient clinics, there have been few reports of clinical trials of art therapy intervention [11]. Bar-Sela et al. [11] demonstrated that art therapy improves depression and influences fatigue levels in cancer patients on chemotherapy [11]. Art therapy interventions differ in their approaches (e.g., anthroposophical, art pedagogical, and artbased) and in their applied methods and materials as well as the context in which they take place (e.g., facilities, length of the intervention). Generally, art therapy interventions are led by art therapists [34]. Considerable stress related to the diagnosis, surgery, and treatment was observed in many breast cancer patients. Almost 50\% women with early breast cancer suffered from depression, anxiety, or both in the first year after diagnosis [35]. In radiotherapy, higher levels of stress have been observed among women than among men, and women with breast cancer reported the highest levels [36]. More women than men participated in this study. This phenomenon, which prefers art therapy in women, has been described [11]. The art therapy used in this study was based on appreciation of famous paintings. The participants could discuss the pictures with the art therapist leading to more free-flowing communication regarding their current physical and emotional state. Although art therapy did not significantly improve fatigue or QoL, generalized linear mixed models showed that there was no deterioration of fatigue or QoL during radiotherapy. Art therapy is worth considering as a positive influence on cancer patients receiving radiotherapy.

The main obstacle to accrual was poor insight for art therapy. At first impression, participants seem to find art therapy to be strange. Some of the participants said it hard to find additional time for art therapy. Self-selection to participate in art therapy is another limitation. The participants might already have positive thoughts about art therapy. We used several famous paintings as art therapy. However, the variations in the content of art therapy could also cause difficulty in determining efficacy and reliability. In terms of site for radiotherapy, breast or chest wall was most common site in this study. Various site of radiotherapy is needed to confirm role of art therapy. This is the single-arm study. Non-specific placebo effects cannot be excluded as possible explanations for the results. Therefore, a randomized controlled trial with more restrictive eligibility criteria is warranted.

In conclusion, fatigue and $\mathrm{QoL}$ in cancer patients with art therapy did not deteriorate during the radiotherapy period. Given the single-arm small number of participants and the pilot design, our studies provide a good basis demonstrating that art therapy of appreciation for famous paintings is worthy of further studies on fatigue and QoL improvement. This therapy can play an important role in routine practice among cancer patients during radiotherapy. 


\section{Conflict of Interest}

No potential conflict of interest relevant to this article was reported.

\section{Acknowledgments}

The authors would like to thank So-Jeong Woo, Eunjung Kim, Changbea Shon, Yun Sun Oh, So Jung An, Jieun Jeong, Soyeon Park, Yunjeong Park, Soo Bin Choi, Sun Ok Kang, Jeom Im Jeong, Yoojung Kang, and Da Un Sun at CHA University for helping with the art therapy.

\section{References}

1. Forlenza MJ, Hall P, Lichtenstein P, Evengard B, Sullivan PF. Epidemiology of cancer-related fatigue in the Swedish twin registry. Cancer 2005;104:2022-31.

2. Richardson A. Measuring fatigue in patients with cancer. Support Care Cancer 1998;6:94-100.

3. Cheon PM, Pulenzas N, Zhang L, et al. Fatigue scores in patients receiving palliative radiotherapy for painful bone metastases. Support Care Cancer 2015;23:2097-103.

4. Lawrence DP, Kupelnick B, Miller K, Devine D, Lau J. Evidence report on the occurrence, assessment, and treatment of fatigue in cancer patients. J Natl Cancer Inst Monogr 2004;(32):40-50.

5. Montgomery GH, David D, Kangas $M$, et al. Randomized controlled trial of a cognitive-behavioral therapy plus hypnosis intervention to control fatigue in patients undergoing radiotherapy for breast cancer. J Clin Oncol 2014;32:557-63.

6. Jacobsen PB, Hann DM, Azzarello LM, Horton J, Balducci $\mathrm{L}$, Lyman $\mathrm{GH}$. Fatigue in women receiving adjuvant chemotherapy for breast cancer: characteristics, course, and correlates. J Pain Symptom Manage 1999;18:233-42.

7. Goldstein D, Bennett $B$, Friedlander $M$, Davenport $T$, Hickie I, Lloyd A. Fatigue states after cancer treatment occur both in association with, and independent of, mood disorder: a longitudinal study. BMC Cancer 2006;6:240.

8. Monga U, Kerrigan AJ, Thornby J, Monga TN. Prospective study of fatigue in localized prostate cancer patients undergoing radiotherapy. Radiat Oncol Investig 1999;7:178-85.

9. Janaki MG, Kadam AR, Mukesh $S$, et al. Magnitude of fatigue in cancer patients receiving radiotherapy and its short term effect on quality of life. J Cancer Res Ther 2010;6:22-6.

10. Ahlberg K, Ekman T, Gaston-Johansson F, Mock V. Assessment and management of cancer-related fatigue in adults. Lancet 2003;362:640-50.

11. Bar-Sela G, Atid L, Danos S, Gabay N, Epelbaum R. Art therapy improved depression and influenced fatigue levels in cancer patients on chemotherapy. Psychooncology 2007;16:980-4.

12. Jereczek-Fossa BA, Marsiglia HR, Orecchia R. Radiotherapyrelated fatigue. Crit Rev Oncol Hematol 2002;41:317-25.

13. Hwang SS, Chang VT, Cogswell J, Kasimis BS. Clinical relevance of fatigue levels in cancer patients at a Veterans Administration Medical Center. Cancer 2002;94:2481-9.

14. Malchiodi C. Medical art ther with adults. London, UK: Jessica Kingsley; 1999.

15. Svensk AC, Oster I, Thyme KE, et al. Art therapy improves experienced quality of life among women undergoing treatment for breast cancer: a randomized controlled study. Eur J Cancer Care (Engl) 2009;18:69-77.

16. Nainis NA. Approaches to art therapy for cancer inpatients: research and practice considerations. Art therapy 2008;25:115-21.

17. Archer S, Buxton S, Sheffield D. The effect of creative psychological interventions on psychological outcomes for adult cancer patients: a systematic review of randomised controlled trials. Psychooncology 2015;24:1-10.

18. Nainis $N$, Paice JA, Ratner J, Wirth JH, Lai J, Shott S. Relieving symptoms in cancer: innovative use of art therapy. J Pain Symptom Manage 2006;31:162-9.

19. Luzzatto P, Gabriel B. The creative journey: a model for shortterm group art therapy with posttreatment cancer patients. Art Ther 2000;17:265-9.

20. Wood MJ, Molassiotis A, Payne S. What research evidence is there for the use of art therapy in the management of symptoms in adults with cancer? a systematic review. Psychooncology 2011;20:135-45.

21. Reynolds MW, Nabors L, Quinlan A. The effectiveness of art therapy: does it work? Art Ther 2000;17:207-13.

22. Monti DA, Peterson C, Kunkel EJ, et al. A randomized, controlled trial of mindfulness-based art therapy (MBAT) for women with cancer. Psychooncology 2006;15:363-73.

23. Mendoza TR, Wang XS, Cleeland CS, et al. The rapid assessment of fatigue severity in cancer patients: use of the Brief Fatigue Inventory. Cancer 1999;85:1186-96.

24. Yun YH, Wang XS, Lee JS, et al. Validation study of the Korean version of the brief fatigue inventory. J Pain Symptom Manage 2005;29:165-72.

25. FACIT. org. Functional assessment of chronic illness therapy [Internet]. Elmhurst, IL: FACIT. org; c2010 [cited 2015 Dec 30]. Available from: $h$ ttp://www.facit.org/FACITOrg/Questionnaires.

26. Webster K, Cella D, Yost K. The Functional Assessment of Chronic Illness Therapy (FACIT) Measurement System: properties, applications, and interpretation. Health Qual Life Outcomes 2003;1:79.

27. Purcell A, Fleming J, Bennett S, McGuane K, Burmeister B, Haines T. A multidimensional examination of correlates of fatigue during radiotherapy. Cancer 2010;116:529-37. 
28. Zeng $L$, Koo K, Zhang $L$, et al. Fatigue in advanced cancer patients attending an outpatient palliative radiotherapy clinic as screened by the Edmonton Symptom Assessment System. Support Care Cancer 2012;20:1037-42.

29. Alcantara-Silva TR, Freitas-Junior R, Freitas NM, Machado GD. Fatigue related to radiotherapy for breast and/or gynaecological cancer: a systematic review. J Clin Nurs 2013;22:2679-86.

30. Smets EM, Visser MR, Willems-Groot AF, et al. Fatigue and radiotherapy: $(A)$ experience in patients undergoing treatment. Br J Cancer 1998;78:899-906.

31. Noal S, Levy C, Hardouin A, et al. One-year longitudinal study of fatigue, cognitive functions, and quality of life after adjuvant radiotherapy for breast cancer. Int J Radiat Oncol Biol Phys 2011;81:795-803.

32. Bower JE, Ganz PA, Desmond KA, Rowland JH, Meyerowitz
BE, Belin TR. Fatigue in breast cancer survivors: occurrence, correlates, and impact on quality of life. J Clin Oncol 2000;18:743-53.

33. Wilson PM. The UK Expert Patients Program: lessons learned and implications for cancer survivors' self-care support programs. J Cancer Surviv 2008;2:45-52.

34. Geue K, Goetze $H$, Buttstaedt M, Kleinert E, Richter D, Singer S. An overview of art therapy interventions for cancer patients and the results of research. Complement Ther Med 2010;18:160-70.

35. Burgess $C$, Cornelius V, Love $S$, Graham J, Richards $M$, Ramirez A. Depression and anxiety in women with early breast cancer: five year observational cohort study. BMJ 2005;330:702.

36. Sehlen $\mathrm{S}$, Hollenhorst $H_{1}$ Schymura B, et al. Psychosocial stress in cancer patients during and after radiotherapy. Strahlenther Onkol 2003;179:175-80. 